\title{
THE DIFFERENCE OF USING SMARTPHONES AND THE PERCEPTION OF FEAR OF MISSING OUT AMONG COLLEGE STUDENTS - A PRELIMINARY STUDY
}

\author{
Kustim Wibowo, Indiana University of Pennsylvania, Kustim.Wibowo@iup.edu \\ Azad I. Ali, Indiana University of Pennsylvania, $\underline{\text { azad.ali@iup.edu }}$
}

\begin{abstract}
The introduction of smartphones and social media helped the life of many students while pursuing their education. They helped students in their communication, in searching for information, shaped their social life and in other different ways that are beyond the scope of this study. However, along with these positive outcomes came some unfavorable effects that students experience as a result excessive use of smartphones and social media. Among these effects is a phenomenon termed as the Fear of Missing Out (or FOMO) which is the topic of discussion in many recent research studies.

This paper is about studying the effect of smart phones and social media among college students. It explains about the experience of FOMO among students and the factors that contribute to it. It also examines the different uses of smart phones and social media at different levels of college education and, freshmen students versus non freshmen students. The study lays the ground to conduct further research specifically on FOMO based on the findings in this study.
\end{abstract}

Keywords: Social media, smartphone addiction, internet addiction, anxiety, depression

\section{INTRODUCTION}

The use of smartphones in the classroom has been a controversial subject for some time. Some consider it helpful to the students to retain information, to schedule appointment, to search the web and in particular useful during emergency situations (Buck, McInnis, \& Randolph, 2013). At the same time, some consider using smartphones in the classroom to be annoying, distracting and as disrespectful (Ali \& Smith, 2015). Nevertheless, both sides agree that there is improper use of mobile phones in the classroom and this in turn is causing alarm among many about the negative effect of using smart phones in the classroom.

Despite the different opinions expressed about the use of smartphones, some studies approach the explanation of using mobile phone from the motives that lead students to use them in inappropriate times. Recent studies attribute this improper use of cell phones to a phenomenon called FOMO (Fear of Missing Out) as the main cause that lead students to improper use of cell phones in the classroom (Hetz et al, 2015, Hodkinson, 2019). The perception is that more students at early stages of their academic programs (at freshman level) experience FOMO than students at other levels of their academic study.

This study is about the use of smartphone in the classroom and the contribution to FOMO. It uses a survey conducted to collect data about using smartphones it the classroom. It examines the use of smartphones in the classroom and social media.

The remainder of this study is divided into the following sections:

- The first section provides a literature review about FOMO and how it affects students at different levels of their studies

- The second section explains about research methodology that followed here

- The third section explains the data collection and data analysis results

- The last section provides conclusion of the study and suggestions for future research 


\section{Issues in Information Systems}

Volume 21, Issue 2, pp. 158-166, 2020

\section{LITERATURE REVIEW}

Imagine you are a college freshman living, for the first time in your life, with only your peers. Your co-ed dormitory, located in the heart of one of North America's most dynamic cities, is buzzing on this particular Friday evening as everyone is getting ready to go out. Yet while the dorm is pulsing with anticipation of a memorable night downtown, you have decided to work on a term paper due on Monday. Consider how your studying experience will be altered by the knowledge that your friends will be out having a great time while you remain with only your unfinished paper as company. It seems likely that, even with excellent willpower and study habits, your studying will be affected by what you know you could be doing, and you will be distracted by nagging thoughts and anxiety about missing out on a potentially exciting experience. Commonly referred to as "fear of missing out", or "FOMO", this is a salient experience for many young people. (Milyavskaya et al, 2018, p. 725).

The above quote explained a potential scenario that describes FOMO without mentioning or noting the use of technology, smartphones, or social media. This is true because FOMO as a phenomenon existed long before the advances of technology or social media introduction. Herman (2010) is accredited with being to identify the phenomena that is Fear Of Missing Out (FOMO) in the 1990s. A Harvard MBA student, Patrick McGinnis, who is credited with popularizing it when he wrote about it in 2004 in The Harbus, the Harvard Business School's student newspaper (McGinnis, 2020).

Dempsey et al. (2019) suggested that the proliferation of social media has amplified the effects of FOMO, and gave an example making it easier to than ever to be aware of experiences on which is missing out. Amandeep (2018) echoed similar thing and noted that social media contribute to the psychological wellbeing of many through enhanced communication. These are examples of positive experiences of social media and many other can be noted. However, social media (and the excessive use of it) have detrimental effect on many.

In a study conducted by Hunt et al. (2018) and suggested that there is considerable evidence to link social media with reduction to wellbeing. The same study connected the time spent on screen activities with depressive symptoms and risk of suicide outcomes. While the risk of suicidal outcomes may sound too extreme and could be complicated by many other factors, but the risk of depression is closely looming, and other studies indicate this connection to social media use. Among these is a study by Dempsey et al (2019) that directly associated social media excessive use that lead to depression. The same study used the term PFU (problematic use of Facebook) as one of the causes that lead to depression. In other words, excessive use of social media causes addiction that leads to direct disengagement from society which eventually leads to isolation and to depression.

Additional studies extended the discussion of social networking sites to include discussion about FOMO. Benjamin et al (2015) conducted a study to examine associations between FOMO, alcohol use, and negative alcohol-related consequences among college students. The study found that higher FoMOs was associated with experiencing more negative alcohol-related consequences. The same study also found higher FOMOs was also associated with consuming a higher quantity of alcoholic drinks per session.

Gezgin et al. (2019) contrasted FOMO with a term called Nomophbia which is the fear of no mobile phone. Gezgin further noted that younger generation (called them generation $\mathrm{Y}$ and $\mathrm{Z}$ ) are able to get addiction to social media in this age of technology. Gezgin further explained different points as shown in the following quote:

Behavior of checking mobile applications all the time causes stress and anxiety in the individual after a while, and the younger generation tends to spend much time on social media to eliminate these anxieties. The studies investigating the prevalence of Nomophobia and FoMO among the younger 
generation show that the common ground of these two disorders is excessive use of smartphones, mobile internet, and social media (p. 734).

The basic conclusion that can be drawn from the literature review is that FOMO is a major problem that faces many students. The root of FOMO although may be related to other personal issues, but mobile phone use and social media contribute to a large extent to the increasing of FOMO among students.

\section{RESEARCH METHODOLOGY}

This study used survey method to question that students about their use of cell phones in the classroom and at different levels of interaction in social media. The survey consists of 31 questions, each used a Likert scale of 1-5 that are organized in check boxes across the survey. The checkboxes are organized to make it easier for the students to understand the questions and to select the proper level of agree/disagree with the questions asked.

The question does not ask about personal information, except for the level of the study to determine if the use of cell phones is experienced at different levels of study experience (if freshmen use cell phone and experience FOMO more than other levels). Thus, there are no issues for privacy and anonymity that could be affected from this data collection. The surveys were distributed mainly to undergraduate students and it matches the focus of our study which is to understand the effect of FOMO on Freshen versus other levels of undergraduate students. Data were collected and entered into Excel spreadsheet and were tabulated in different forms as presented in the next section.

There were also open-ended questions that asked the participants what the benefits and disadvantages would be to be connected through smartphone and what would be the best ways to reduce their connection and dependability to the smartphone. All participants voluntarily involved in the study. No credit towards grade nor financial compensation were awarded to the participants

\section{DATA COLLECTION AND DISCUSSION}

There were 161 participants in this study divided between male and female as shown in the following tablet.

Table 1. Survey Participants

\begin{tabular}{|l|l|l|l|}
\hline Rank & Total & Male & Female \\
\hline Freshman & 69 & $64 \%$ & $36 \%$ \\
\hline Non-freshman & 92 & $70 \%$ & $30 \%$ \\
\hline Total & 161 & $67 \%$ & $33 \%$ \\
\hline
\end{tabular}

The non-freshman students consist of sophomore $30 \%$, junior $47 \%$, and senior $23 \%$, in total, there are $70 \%$ nonfreshman participants are junior and senior. The majority of freshman is 18 years old (70\%), while the majority of non-freshman is 20 years old (37\%) and the next group is 21 years old (30\%). The majority of non-freshman participants are in average 2 to 3 years older than freshman participants.

The overwhelming participants (99\%) specified that they have at least one personal computer, one smartphone, and Internet connection in their residence. Given the university provides Internet access to all across the campus, the availability of these facilities shows that most of them have access to the Internet through their computer or smartphone from anywhere at any time.

However only $87 \%$ of freshman and $77 \%$ of non-freshman participants reported that they carry their smartphone around campus. Others reported that they carry backpack, computer, or textbook. More freshman than non-freshman carry their smartphone anywhere they go. 


\section{Issues in Information Systems}

Volume 21, Issue 2, pp. 158-166, 2020

\section{Access to Social Media Data}

Both freshman and non-freshman access different types of Social Media in their daily communication. There are seven Social Media Network types and twenty social media names are listed in the questionnaire. This is illustrated in table 2 below.

The most popular is YouTube, freshman have been utilized it in average of 7.33 years and non-freshman have been utilized it in average of 7.53 year. The second most popular is Instagram, freshman have been utilized it in average of 5.10 years and non-freshman have been utilized it in average of 5.21 years. The third most popular is Snapchat, freshman have been utilized it in average of 5.10 years and non-freshman have been utilized it in average of 5.21 years. The first three most popular media apps are all Media Sharing Networks type. In this network apps, their member activities are to find and share photos, video, live video, and other media online.

Table 2. Social Media Utilization

\begin{tabular}{|l|l|l|l|l|r|}
\hline & \multicolumn{3}{|c}{ Social Media } & Freshman & Non-Freshman \\
\hline$\#$ & Types & $\#$ & Names & Avg-Years & Avg-Years \\
\hline 1 & Social Network & 1 & Facebook & 4.23 & 5.30 \\
\hline & & 2 & Twitter & 2.83 & 4.40 \\
\hline 2 & Media Sharing Network & 3 & Linkedin & 0.41 & 1.01 \\
\hline & & 4 & Instagram & 5.10 & 5.21 \\
\hline & & 5 & Snapchat & 4.67 & 4.83 \\
\hline 3 & Discussion Forum & 6 & YouTube & 7.33 & 7.53 \\
\hline & & 7 & Reddit & 0.43 & 0.47 \\
\hline & & 8 & Quora & 0.06 & 0.07 \\
\hline 4 & Bookmarking \& Content & 9 & Digg & 0.00 & 0.04 \\
\hline & & 10 & Pinterest & 1.03 & 1.32 \\
\hline 5 & Consumer Review & 11 & Flipboard & 0.00 & 0.10 \\
\hline & & 12 & Yelp & 0.09 & 0.12 \\
\hline & & 13 & Zomato & 0.00 & 0.02 \\
\hline 6 & Blogging \& Publishing & 14 & TripAdvisor & 0.03 & 0.04 \\
\hline & & 15 & WordPress & 0.00 & 0.09 \\
\hline & & 16 & Tumblr & 0.28 & 0.50 \\
\hline 7 & Social Shopping & 17 & Medium & 0.00 & 0.07 \\
\hline & & 18 & Polyvore & 0.00 & 0.07 \\
\hline & & 19 & Esty & 0.22 & 0.34 \\
\hline
\end{tabular}

The average age different between freshman and non-freshman is between 2 to 3 years, but their average length of using YouTube, Instagram, and Snapchat are about the same. This indicate that freshman have started using them 2 to 3 years younger than non-freshman.

The fourth most popular is Facebook, freshman have been utilized it in average of 4.23 years and non-freshman have been utilized it in average of 5.30 years. The fifth most popular is Twitter, freshman have been utilized it in average of 2.23 years and non-freshman have been utilized it in average of 4.40 years. The fourth and fifth most popular media apps are Social Networks type. In this network, their member activities are to connect with people (and brands) online. 
The sixth most popular is Pinterest, freshman have been utilized it in average of 1.03 years and non-freshman have been utilized it in average of 1.32 years. Pinterest is Bookmarking \& Content Curation Network type. In this network, their member activities are to discover, save, share, and discuss new and trending content and media.

Linkend surprisingly is the seventh most popular Social Media app. Freshman have been utilized it in average of 0.41 years and non-freshman have been utilized it in average of 1.01 years. Like Facebook and Twitter, Linkedin is Social Networks type. Linkedin helps its members to develop a strong digital footprint, research companies and industries, find and apply for jobs, and build a strong professional network.

The rest of Social Media apps in average were accessed and utilized by less than a year by both freshman and nonfreshman participants.

\section{Computer and Phone Activities on Campus Data}

There is a slight difference on how freshman and non-freshman work around their computer and phone. Freshman check their computer 1.9 time while non-freshman check 1.6 times in an hour. However, they check their smartphone much more often, freshman check their smartphone 12.5 times and non-freshman spend 10.9 times in an hour. This is show in table 3 below.

Table 3. Computer and Smartphone Utilization

\begin{tabular}{|l|l|l|}
\hline Description & Freshman & Non-freshman \\
\hline Check your computer in an hour & 1.9 times & 1.6 times \\
\hline Check your smartphone in an hour & 12.5 times & 10.9 times \\
\hline Work on college related with computer in 24 hours & 4.0 hours & 3.6 hours \\
\hline Work on college related with smartphone in 24 hours & 1.4 hours & 1.8 hours \\
\hline Work on non-college related with computer in 24 hours & 2.1 hours & 2.3 hours \\
\hline Work on non-college related with smartphone in 24 hours & 5.8 hours & 5.3 hours \\
\hline
\end{tabular}

In 24 hours, both freshman and non-freshman spend almost the same amount of hours working in their computer and smartphone. Freshman spend about 4 computer hours and about 1.4 smartphone hours on college related works. Freshman also spend about 2.1 computer hours and about 5.8 smartphone hours on non-college related activities. Nonfreshman spend about 3.6 computer hours and about 1.8 smartphone hours on college related works. Non-freshman also spend about 2.3 computer hours and about 5.3 smartphone hours on non-college related activities.

\section{Data about Things first to check in the morning}

Snapchat is the favorite app for both freshman and non-freshman (50.72\% and 27.17\% respectively) to checked first time in the morning. Snapchat is a mobile messaging application used to share photos, videos, text, and drawings. It's free to download the app and free to send messages using it. Therefore, it has become hugely popular in a very short space of time, especially with young people. The next most check apps is weather, follow by Message, Email, and News. Table 4 below shows summary of the data about first app to use in the morning.

Table 4. First app that will be checked 1st time in the morning.

\begin{tabular}{|l|l|l|l|l|l|}
\hline College ranks & Snapchat & Weather & Message & Email & News \\
\hline Freshman & $50.72 \%$ & $10.14 \%$ & $8.70 \%$ & $1.45 \%$ & $1.45 \%$ \\
\hline Non-freshman & $27.17 \%$ & $4.35 \%$ & $5.43 \%$ & $4.35 \%$ & $3.26 \%$ \\
\hline
\end{tabular}

However, both freshman and non-freshman first check the messages that they received in the morning. The messages that were received through many apps including from Snapchat. The messages will include information such as who 


\section{Issues in Information Systems}

Volume 21, Issue 2, pp. 158-166, 2020

texted them, class cancellation, what friends are doing, plan for today, games scores, and the likes. The specific information they would like to know early in the morning are time, weather, and news. It is not a surprise that Email is the last app they will check for information. With so many more flexible, faster, and free messaging app with advanced data combination and exchange possibilities, Email becoming less attractive to its users. Table 5 below shows the summary of this data.

Table 5. First information that will be checked 1st time in the morning

\begin{tabular}{|l|c|c|c|c|c|}
\hline College ranks & Time & Weather & Message & Email & News \\
\hline Freshman & $8.70 \%$ & $5.60 \%$ & $23.19 \%$ & $0.00 \%$ & $4.35 \%$ \\
\hline Non-freshman & $8.70 \%$ & $6.52 \%$ & $20.65 \%$ & $1.09 \%$ & $13.04 \%$ \\
\hline
\end{tabular}

\section{Social Media Activities Data}

There are two activities that both freshman and non-freshman are very often and moderately conduct on social media. They are sending/receiving text and watching videos/movies. In both activities, freshman slightly do more than nonfreshman. In sending/receiving text, freshman in average do $10 \%$ more than non-freshman $(91.30 \%$ compare to $83.70 \%)$. While in watching videos/movies, freshman in average do $10 \%$ more than non-freshman $(81.16 \%$ compare to $76.09 \%$ ). The next two activities that both freshman and non-freshman are very often and moderately conduct on social media are initiating/sending video and sending/receiving email. Both freshman and non-freshman are about the same interest initiating/sending videos than non-freshman (43.47\% compare to $42.39 \%)$. Freshman in average slightly more in sending/receiving email than non-freshman (43.47\% compare to $40.22 \%)$.

Table 6. Activities they do on the social media

\begin{tabular}{|c|c|c|c|c|c|}
\hline & Very & \multirow{2}{*}{ Moderate } & \multirow{2}{*}{ Occasionally } & \multirow{2}{*}{ Rarely } & \multirow{2}{*}{ Never } \\
\hline Freshman & Often & & & & \\
\hline text (sending and receiving) & $59.42 \%$ & $31.88 \%$ & $8.70 \%$ & $0.00 \%$ & $0.00 \%$ \\
\hline video and video call (initiating and sending) & $11.59 \%$ & $31.88 \%$ & $36.23 \%$ & $17.39 \%$ & $2.90 \%$ \\
\hline email (sending and receiving) & $10.14 \%$ & $33.33 \%$ & $43.48 \%$ & $13.04 \%$ & $0.00 \%$ \\
\hline watching videos/movies & $49.28 \%$ & $31.88 \%$ & $15.94 \%$ & $1.45 \%$ & $0.00 \%$ \\
\hline reading books/news/magazines & $1.45 \%$ & $15.94 \%$ & $36.23 \%$ & $39.13 \%$ & $7.25 \%$ \\
\hline Play games & $14.49 \%$ & $18.84 \%$ & $18.84 \%$ & $28.99 \%$ & $18.84 \%$ \\
\hline & Very & \multirow{2}{*}{ Moderate } & \multirow{2}{*}{ Occasionally } & \multirow{2}{*}{ Rarely } & \multirow{2}{*}{ Never } \\
\hline Non-freshman & Often & & & & \\
\hline text (sending and receiving) & $50.00 \%$ & $33.70 \%$ & $14.13 \%$ & $2.17 \%$ & $0.00 \%$ \\
\hline video and video call (initiating and sending) & $16.30 \%$ & $26.09 \%$ & $35.87 \%$ & $16.30 \%$ & $5.43 \%$ \\
\hline email (sending and receiving) & $14.13 \%$ & $26.09 \%$ & $32.61 \%$ & $21.74 \%$ & $5.43 \%$ \\
\hline watching videos/movies & $51.09 \%$ & $25.00 \%$ & $18.48 \%$ & $4.35 \%$ & $1.09 \%$ \\
\hline reading books/news/magazines & $9.78 \%$ & $20.65 \%$ & $30.43 \%$ & $32.61 \%$ & $6.52 \%$ \\
\hline Play games & $17.39 \%$ & $6.52 \%$ & $28.26 \%$ & $33.70 \%$ & $14.13 \%$ \\
\hline
\end{tabular}

\section{Data about Reason for using smartphone/computer}

Both freshman and non-freshman are strongly agree and agree that the reason they are using smartphone/computer is to communicate with friends and family. Freshman more than non-freshman in communicating with their friends (100\% compare to $97.83 \%$ ). While in communicate with family freshman is slightly more than non-freshman (98.55\% 
compare to 95.65\%). The next key reason they are using smartphone/computer is to find interesting current news/situation reason. Non-freshman more interested than freshman (81.52\% compare to $69.56 \%)$. All this data is shown in table 7 below

Table 7: Why they are using smartphone/computer

\begin{tabular}{|l|r|r|r|r|r|}
\hline & Strongly & & Unable to & & Strongly \\
\hline Freshman & Agree & \multicolumn{1}{|l|}{ Agree } & Judge & Disagree & Disagree \\
\hline to communicate with family & $59.42 \%$ & $39.13 \%$ & $1.45 \%$ & $0.00 \%$ & $0.00 \%$ \\
\hline to communicate with friends & $72.46 \%$ & $27.54 \%$ & $0.00 \%$ & $0.00 \%$ & $0.00 \%$ \\
\hline to find interesting current news/situation & $33.33 \%$ & $36.23 \%$ & $21.74 \%$ & $8.70 \%$ & $0.00 \%$ \\
\hline to look for my old friend's current information & $10.14 \%$ & $17.39 \%$ & $33.33 \%$ & $34.78 \%$ & $4.35 \%$ \\
\hline to look for my friend's current information & $11.59 \%$ & $40.58 \%$ & $28.99 \%$ & $15.94 \%$ & $2.90 \%$ \\
\hline to look for my prospective friend's information & $5.80 \%$ & $23.19 \%$ & $44.93 \%$ & $24.64 \%$ & $1.45 \%$ \\
\hline & Strongly & & Unable to & & Strongly \\
\hline Non-freshman & Agree & Agree & Judge & Disagree & Disagree \\
\hline to communicate with family & $55.43 \%$ & $40.22 \%$ & $3.26 \%$ & $1.09 \%$ & $0.0 \%$ \\
\hline to communicate with friends & $70.65 \%$ & $27.17 \%$ & $2.17 \%$ & $0.00 \%$ & $0.0 \%$ \\
\hline to find interesting current news/situation & $31.52 \%$ & $50.00 \%$ & $10.87 \%$ & $6.52 \%$ & $1.1 \%$ \\
\hline to look for my old friend's current information & $9.78 \%$ & $27.17 \%$ & $20.65 \%$ & $35.87 \%$ & $6.5 \%$ \\
\hline to look for my friend's current information & $11.96 \%$ & $44.57 \%$ & $19.57 \%$ & $17.39 \%$ & $6.5 \%$ \\
\hline to look for my prospective friend's information & $8.70 \%$ & $18.48 \%$ & $33.70 \%$ & $28.26 \%$ & $10.9 \%$ \\
\hline
\end{tabular}

\section{Data About Updates Students are Afraid They Miss}

There are two group of information that the survey participants afraid to oversight: updates from related family/friends, and updates from related university/courses/professors. Both group of information are extremely and moderately important for them.

Freshman slightly more afraid than non-freshman in missing information from their family/friends (freshman average 73.19\% and non-freshman 61.41\%). In the updates from university/courses/professor. Freshman are also more afraid than non-freshman in missing information from university/courses/professors (freshman 76.33\% compare to 72.10\%). Table 7 below shows this data 
Table 8. What updates they afraid to oversight

\begin{tabular}{|l|r|r|r|r|r|}
\hline & Extremely & \multicolumn{1}{l|}{ Moderately } & \multicolumn{1}{l|}{ Neutral } & \multicolumn{1}{l}{ Low } & \multicolumn{1}{l|}{ Not } \\
\hline Freshman & Important & Important & Important & Important & Important \\
\hline any updates from your family & $44.93 \%$ & $28.99 \%$ & $18.84 \%$ & $7.25 \%$ & $0.00 \%$ \\
\hline any updates from your friends & $24.64 \%$ & $47.83 \%$ & $21.74 \%$ & $5.80 \%$ & $0.00 \%$ \\
\hline any updates from your neighbors & $4.35 \%$ & $10.14 \%$ & $42.03 \%$ & $17.39 \%$ & $26.09 \%$ \\
\hline any updates from your music starts & $0.00 \%$ & $10.14 \%$ & $26.09 \%$ & $23.19 \%$ & $40.58 \%$ \\
\hline any updates from your movie stars & $1.45 \%$ & $2.90 \%$ & $26.09 \%$ & $23.19 \%$ & $46.38 \%$ \\
\hline any updates from your nfl/nba/nhl, etc stars & $5.80 \%$ & $13.04 \%$ & $23.19 \%$ & $24.64 \%$ & $33.33 \%$ \\
\hline any updates from your courses & $37.68 \%$ & $37.68 \%$ & $20.29 \%$ & $4.35 \%$ & $0.00 \%$ \\
\hline any updates from your teacher/professor & $39.13 \%$ & $40.58 \%$ & $17.39 \%$ & $2.90 \%$ & $0.00 \%$ \\
\hline any updates from your school/university & $34.78 \%$ & $39.13 \%$ & $15.94 \%$ & $10.14 \%$ & $0.00 \%$ \\
\hline any updates from your political representative & $1.45 \%$ & $14.49 \%$ & $42.03 \%$ & $21.74 \%$ & $20.29 \%$ \\
\hline & Extremely & Moderately & Neutral & Low & Not \\
\hline Non-freshman & Important & Important & Important & Important & Important \\
\hline any updates from your family & $36.96 \%$ & $28.26 \%$ & $26.09 \%$ & $6.52 \%$ & $2.17 \%$ \\
\hline any updates from your friends & $22.83 \%$ & $34.78 \%$ & $28.26 \%$ & $10.87 \%$ & $3.26 \%$ \\
\hline any updates from your neighbors & $5.43 \%$ & $7.61 \%$ & $38.04 \%$ & $23.91 \%$ & $25.00 \%$ \\
\hline any updates from your music starts & $6.52 \%$ & $6.52 \%$ & $26.09 \%$ & $29.35 \%$ & $31.52 \%$ \\
\hline any updates from your movie stars & $4.35 \%$ & $4.35 \%$ & $26.09 \%$ & $28.26 \%$ & $36.96 \%$ \\
\hline any updates from your nfl/nba/nhl, etc stars & $9.78 \%$ & $11.96 \%$ & $22.83 \%$ & $20.65 \%$ & $34.78 \%$ \\
\hline any updates from your courses & $43.48 \%$ & $33.70 \%$ & $18.48 \%$ & $2.17 \%$ & $1.09 \%$ \\
\hline any updates from your teacher/professor & $36.96 \%$ & $35.87 \%$ & $22.83 \%$ & $3.26 \%$ & $1.09 \%$ \\
\hline any updates from your school/university & $35.87 \%$ & $30.43 \%$ & $26.09 \%$ & $4.35 \%$ & $3.26 \%$ \\
\hline any updates from your political representative & $10.87 \%$ & $13.04 \%$ & $35.87 \%$ & $19.57 \%$ & $20.65 \%$ \\
\hline
\end{tabular}

\section{CONCLUSION AND RECOMMENDATIONS FOR FUTURE STUDIES}

The result of the data collected from the students did not reveal a significant difference between freshmen and nonfreshmen students in their use of cell phone or their preferences of social media. Any difference is small that can be explained with the margin of error. Similarly, the result of data did not give clear clues whether FOMO is experience more among freshmen or among other students. This is largely due to the fact the questions in the study do not address FOMO to a great depth, instead it is focused on social media.

Based on the data collection and the basic results we have reached from this study, our recommendation is to conduct a study to see the difference in FOMO between the different levels of students. Our next study is intended to gear it more toward FOMO, thus the questions and the design of the study will address FOMO characteristics directly and that is the intention of our next study/

\section{REFERENCES}

Amandeep Dhir, Y. Y. (2018). Online Social Media Fatique and Psychological wellbeing -- A Study of Compulsive Use, Fear of Missing Out, Fatique, Anxiety and Depression. International Journal of Information Management, 40, 141-152. 


\section{Issues in Information Systems}

Volume 21, Issue 2, pp. 158-166, 2020

Buck, J. L., McInnis, E., \& Randolph, C. (2013). The new frontier of education: The impact of smartphone technology in the classroom. In American Society for Engineering Education (Vol. 1, No. 1, pp. 1-11).Dempsey, A. E., O'Brien, K. D., Tiamiyu, M. F., \& Elhai, J. D. (2019). Fear of missing out (FoMO) and rumination mediate relations between social anxiety and problematic Facebook use. Addictive behaviors reports, 9, 100150.

Dossey, L. (2014). FOMO, digital dementia, and our dangerous experiment. Explore: The Journal of Science and Healing, 10(2), 69-73.

Gezgin, D. M., Hamutoğlu, N. B., Sezen-Gültekin, G., \& Yildirim, S. (2019). Preservice teachers' metaphorical perceptions on smartphone, No Mobile Phone Phobia (Nomophobia) and Fear of Missing Out (FoMO). Bartin Üniversitesi Egitim Fakültesi Dergisi, 8(2), 733-783.

Herman, D. (2010). The Fear of missing out (FOMO). Dostępny w World Wide Web: http://www. danherman. com/The-Fear-of-Missing-Out-(FOMO)-by-Dan-Herman. html [dostęp: 28.08. 2018].

Hetz, P. R., Dawson, C. L., \& Cullen, T. A. (2015). Social media use and the fear of missing out (FoMO) while studying abroad. Journal of Research on Technology in Education, 47(4), 259-272.

Hunt, M. G., Marx, R., Lipson, C., \& Young, J. (2018). No more FOMO: Limiting social media decreases loneliness and depression. Journal of Social and Clinical Psychology, 37(10), 751-768.

Hodkinson, C. (2019). 'Fear of Missing Out'(FOMO) marketing appeals: A conceptual model. Journal of Marketing Communications, 25(1), 65-88.

McGinnis, P. J. (2020). Fear of Missing Out: Practical Decision-Making in a World of Overwhelming Choice. Sourcebooks, Inc..

Milyavskaya, M., Saffran, M., Hope, N., \& Koestner, R. (2018). Fear of missing out: prevalence, dynamics, and consequences of experiencing FOMO. Motivation \& Emotion, 42(5), $725-737$. https://doi.org/10.1007/s11031-018-9683-5

Perreault, M. F., \& Perreault, G. P. (2020). Mobile Gaming Strategic Communication and Fear of Missing Out (FoMO) in Fan Culture: A Case Study of Final Fantasy Brave Exvius. In Multidisciplinary Perspectives on Media Fandom (pp. 253-269). IGI Global. 